\title{
Investigation on Physicomechanical Properties and Constitutive Model of Tuff in Mila Mountain Tunnel under Dry and Saturated Conditions
}

\author{
Zhihao He, ${ }^{1,2}$ Xiangjun Pei $\mathbb{D}^{1,2}$ Shenghua Cui $\mathbb{D}^{1},{ }^{1,2}$ Wentai Sun, ${ }^{3}$ Luguang Luo, ${ }^{1,2}$ \\ and Chengruiwei $\mathrm{He}^{4}$ \\ ${ }^{1}$ State Key Laboratory of Geohazard Prevention and Geoenvironment Protection, Chengdu University of Technology, Chengdu, \\ Sichuan 610059, China \\ ${ }^{2}$ College of Environmental and Civil Engineering, Chengdu University of Technology, Chengdu, Sichuan 610059, China \\ ${ }^{3}$ CCCC Second Highway Consultants Co., Ltd., Wuhan, Hubei 430070, China \\ ${ }^{4}$ College of Civil Engineering, Hefei University of Technology, Hefei, Anhui 230009, China
}

Correspondence should be addressed to Xiangjun Pei; peixj0119@tom.com

Received 18 April 2021; Accepted 12 June 2021; Published 15 July 2021

Academic Editor: Guowen Xu

Copyright $\odot 2021$ Zhihao He et al. This is an open access article distributed under the Creative Commons Attribution License, which permits unrestricted use, distribution, and reproduction in any medium, provided the original work is properly cited.

\begin{abstract}
Many tunnel engineering accidents are generally caused by water softening tuff of high porosity. Experimental and theoretical analytical methods, including rock ultrasonic testing, X-ray diffraction (XRD), microscopic observation, uniaxial compression test, and scanning electron microscope (SEM), are employed to analyze the physicomechanical properties of tuff in Mila Mountain tunnel under dry and saturated conditions. Then, the mechanism of tuff softening in water is explained. Finally, the statistical damage constitutive model of tuff is established. It was revealed that the tuff compositions were dominated by quartz and clay minerals accounting for more than $90 \%$, and clay minerals, anhydrite, and pyrite were mainly soluble minerals. After being saturated with water, the soluble minerals in the tuff are dissolved, and the porosity and wave velocity are increased; however, the elastic modulus and peak strength are decreased, indicating that water softening was distinct. Water softening after saturation was due to the mineral compositions and microstructure characteristics of tuff in Mila Mountain tunnel; specifically, as the tuff characterized by high porosity was conductive to water absorption, the soluble minerals in the tuff were corroded and swelled by water, dissolving, loosening, and softening the tuff structure; then, its mechanical behavior was degraded. It was demonstrated by the experimental results consistent with theoretical results that the model can be employed to express the constitutive behavior of tuff in Mila Mountain tunnel under dry and saturation conditions. The findings provide insights into macroscale deterioration of tuffs and theoretical knowledge for the tunnel excavation and support of Mila Mountain tunnel.
\end{abstract}

\section{Introduction}

Tuff, a special kind of rock and widely distributed in earth crust, is formed after sedimentation and high temperature and characterized by lower density, high porosity, and easiness to deform after water softening [1-5]. The issue of tuff strata cannot be avoidable on many engineering constructions, for instance, deep-buried long tunnels [6] and deep underground geological disposal site [7]. Thus, in order to take effective measurements in tuff engineering applications, it is necessary to explain the mechanical characteristics and establish constitutive model of tuff. Recently, there are many studies on tuff in engineering applications [8-10]. For example, owing to good processability, tuffs have been used as building stones all around the world since ancient times [2, 11]. As natural materials, tuffs possess variable chemical, mineralogical, and reactive attributes. Hence, tuffs in building sector are its additional application in cement production $[12,13]$. These research results are conductive to reveal the tuffs characteristics in engineering applications [14].

Meanwhile, there are studies in which physicomechanical features and failure mechanism of the tuffs from several regions 
were determined [15]. It was concluded from these studies that tuffs are a volcanic rock with high porosity and low strength, and the pink tuffs in Midas Monument have higher strength than those of white tuffs [16]. By field investigations and numerical modelling, Salve et al. investigated the flow-field evolution, drainage of fracture flow paths, and seepage characteristics in unsaturated fractured welded stuffs $[17,18]$. In the field of rock mechanics, uniaxial compressive strength (UCS) is one of the most widely used parameters used to evaluate mechanical property of various rock types [19]. Previous studies have suggested that UCS is controlled by total porosity, water saturation, and the type of rock-forming minerals [19]. For example, Martin et al. investigated the mechanical properties and microstructure of tuff under shock condition and pointed out that strength and moduli of tuff significantly degraded at shock condition, which is associated with microstructural damage in the form of microcracks and crushed pores [20]. Li et al. argued that different pore properties lead to different mechanical deterioration and tuff failure mode for tuff [21]. An investigation into the effect of water saturation on deterioration of tuff showed when the initial degree of saturation of tuff exceeded $70 \%$, one freeze-thaw cycle causes a decrease in the uniaxial compressive strength, a decrease in the $P$-wave velocity, and an increase in the porosity of the rock. While when the initial degree of saturation is lower than $70 \%$, one freeze-thaw cycle has minimal effect on the same properties [22]. Togashi et al. found that the maximum and minimum principal strain orientations are rotated by approximately $90^{\circ}$ from the wet state to dry state [23]. These studies on the mechanical characteristics and fracture mechanism of tuffs with different moistures and porosities are conductive to thorough comprehension on the characteristics of high porosity and water softening of tuff. However, considering that the issue of water softening tuffs with high porosity is not avoidable in tunnel engineering, researches are few on the mechanical characteristics and fracture mechanism of tuffs under dry and saturated conditions in the tunnel engineering applications in alpine and high-altitude areas.

In this paper, porosity characteristics, mineral compositions, and microstructural characteristics of tuffs were investigated to figure out the basis of water softening tuffs under dry and saturated conditions through ultrasonic testing on rock mass, $\mathrm{XRD}$, and microscopic observation. In addition, through uniaxial compression and SEM experiments, the mechanical and failure characteristics of tuffs in the tunnel of Mila Mountain were studied to reveal the characteristics of water softening tuffs. According to the above experiments and results, it was concluded that the main reason for water softening tuffs was due to high porosity which was conductive to water absorption, and then, soluble mineral compositions of tuffs were corroded and swelled by water. Furthermore, a constitutive model was established under dry and saturated conditions based on a series of mechanics tests to calculate microfractures in volcanic tuff, which facilitated the numerical analysis of tunnel excavation and support design. The findings provided insights into macroscale deterioration of tuffs and theoretical basis for the tunnel excavation and support of Mila Mountain.

\section{Test Introduction}

2.1. Engineering Background. Mila Mountain tunnel, one of the key highway renovation projects in the section of Nyingchi to Lhasa belonging to the national highway numbered as 318 route in Tibet located at the junction of Gongbo'gyamda County and Maizhokunggar County where the average elevation is $4763.5 \mathrm{~m}$, and the maximum reaches $5020 \mathrm{~m}$, characterized by thin air, low pressure, poor nature, and geological conditions, is an extra-long highway tunnel at the highest elevation in the world designed with double holes in separation for $30 \sim 39 \mathrm{~m}$ in distance, $5727 \mathrm{~m}$ in length for the left hole, and $5720 \mathrm{~m}$ for the right, about $375 \mathrm{~m}$ at the maximum depth, $5.0 \mathrm{~m}$ for the height, and $10.25 \mathrm{~m}$ for the width. The surrounding rocks of the tunnel are dominated by IV and V grade tuffs, accounting for $85 \%$. As shown in Figure 1, tunnel collapse, gushing, mud bursting, and deformation after initial support have occurred frequently in tunnel construction because of tuffs characteristics, for instance, microfractures development, collapse, water softening and decomposition, and dramatic degradation of tuffs mechanical property, etc. According to as-built records, the daily water yield increased from $8000 \mathrm{~m}^{3} / \mathrm{d}$ at the beginning to $12000 \mathrm{~m}^{3} / \mathrm{d}$ at the fault zone, and the maximum water inflow reached $38600 \mathrm{~m}^{3} / \mathrm{d}$. The key to resolving the above problems such as deformation, gushing, and collapse is to reveal the mechanical characteristics of tuffs under dry and saturated conditions; therefore, the tuff at the bursting site in the tunnel of Mila Mountain was selected as the object for experiments. The tuff used in this research was collected from buried depth of $316 \mathrm{~m}$ of Mila Mountain tunnel at Pile no. ZK $4477+371$ in Lhasa, Tibet Autonomous Region, China. Testing specimens have uniform texture, and the mean density is $2.53 \mathrm{~g} / \mathrm{cm}^{3}$.

2.2. Sample Preparation and Test Procedure. The physicomechanical characteristics of tuff are the basis for further analysis of its water deterioration effect, fracture mechanism, and establishment of constitutive model. Therefore, in order to obtain the basic physicomechanical characteristics of tuff in the tunnel of Mila Mountain, rock ultrasonic testing, $\mathrm{X}$-ray diffraction (XRD), microscopic observation, uniaxial compression test, and scanning electron microscope tests were carried out. The specific testing flow is depicted in Figure 2.

Firstly, vacuum saturation test was done on the sample numbered as SAT1 SAT5 by Rock Vacuum Saturation Meter DP-SJA at Rock Mechanics Laboratory of Chengdu University of Technology (CDUT), lasting for $72 \mathrm{~h}$ in order to make sure that the sample was in full saturation.

Secondly, the samples numbered as DRY1 DRY5, SAT1 SAT5 were tested by Automatic Acquisition Acoustic Detector FDP204-SW at the laboratory.

Thirdly, Diffractometer DMAX-3C and Jiangnan XP-213 Transmission Polarized Light Microscope from the test center of CDUT were used to observe the samples' compositions and microstructures under dry and saturated conditions. In X-ray diffraction test, small quantities of 


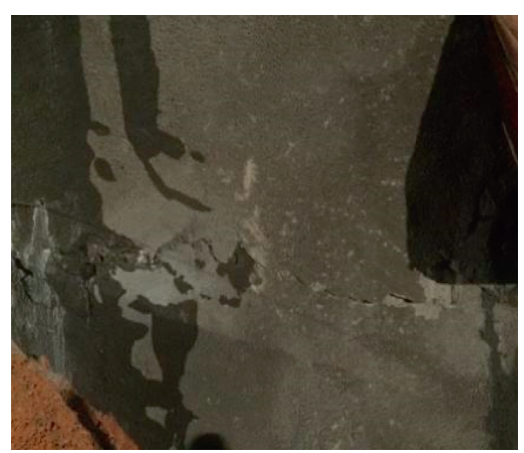

(a)

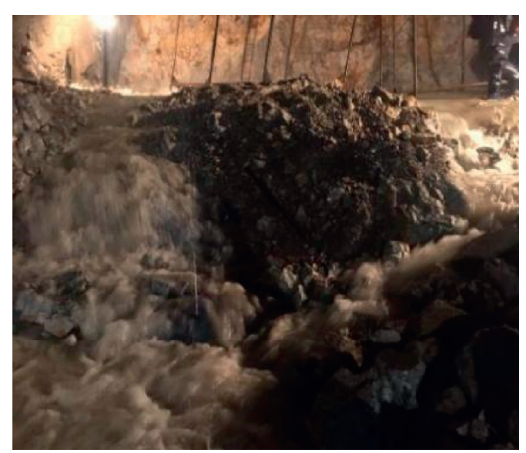

(b)

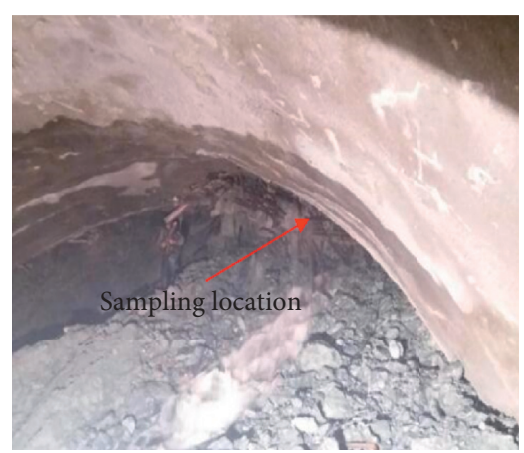

(c)

FIgURE 1: Images of initial supports cracking (a), water inrush phenomenon (b), and sampling points (c) of the Mila Mountain tunnel.

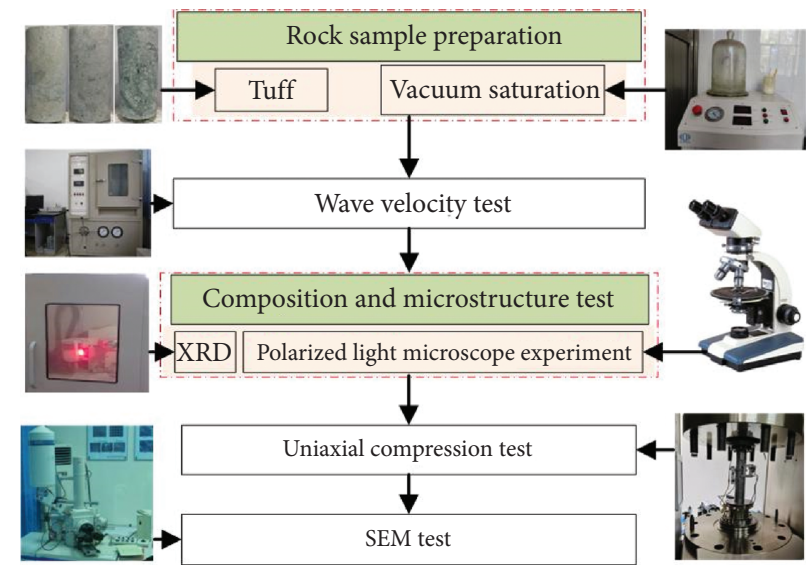

FIgURE 2: Experimental flowchart.

samples in each sample were ground into powders with the grain size within $5 \mathrm{~mm}$; then, the fresh and unweathered powders were screened for cutting, grinding, gluing, slicing, and grinding to achieve the standard thickness, $30 \mu \mathrm{m}$; then, they were observed by microscope on the polarized light microscope experiment.

Fourth, uniaxial compression test was done by MTS815Teststar from the laboratory of CDUT. Grinding machine and abrasive paper were applied to grind both ends of the cylindrical samples whose height is $100 \mathrm{~mm}$. Loading rate was controlled by displacement as recommended by International Society for Rock Mechanics (ISRM) in this test. Specifically, $1 \mathrm{kN}$ force was preloaded to make the rock sample fixed; then, axial loading was carried out at the loading rate of $0.1 \mathrm{~mm} / \mathrm{min}$ until the specimen was failure.

Finally, SEM was used to observe the typical blocks of tuff samples after the above tests using Electron Microscope (Hitachi S-3000N) from CDUT and further to reveal the microfractures characteristics.

\section{Test Results and Analysis}

3.1. Analysis on Structure Characteristics. Mineral compositions analysis, optical microscopic observation, and wave velocity testing were made on tuffs under dry and saturated conditions, in order to explain the effect of water on the microstructure of tuffs in the tunnel of Mila Mountain. The results are shown in Table 1 and Figures 3 and 4 .

As shown in Table 1, the compositions of tuffs in the tunnel of Mila Mountain contained quartz, clay minerals, plagioclase, anhydrite, pyrite, siderite, gypsum, K-feldspar, etc., of which quartz and clay minerals were in proportion of more than $90 \%$. The mineral compositions of the tuffs were unchanged under dry and saturated conditions, while the proportions changed under two different conditions, which was due to water dissolution and corrosion; that is, the clay mineral content in the tuffs under saturated condition was lower $2 \%$ than that under dry condition, and quartz content increased by $3 \%$ in that case.

It can be seen from the rock slice on microscope in Figure 3 that the primary compositions of tuffs in the tunnel of Mila Mountain are volcanic glass (55\%) and matrix (45\%), of which matrix is mainly composed by microlite with grain diameter $10-20 \mu \mathrm{m}$ and little opaque mineral distributed in stellate with grain diameter $50-150 \mu \mathrm{m}$, and volcanic glass is in the shape of nearly round or oval particles with grain diameter $100-250 \mu \mathrm{m}$, or even $300-800 \mu \mathrm{m}$ for less, and the majority of volcanic glass experienced argillization; little is corroded and evolves into dissolved pore. Porosity of sheet is poor, and mainly composed of intragranular pores. Most of the pores are isolated and distributed sporadically, with the grain diameter $50-250 \mu \mathrm{m}$, few can reach $300-400 \mu \mathrm{m}$ which 
TABLe 1: Mineralogical composition of the tested tuff samples (weight \%).

\begin{tabular}{lcccccccc}
\hline Sample no. & Quartz & Clay minerals & Plagioclase & Anhydrite & Pyrite & Siderite & Gypsum & K-feldspar \\
\hline D-1 & 60 & 30 & 3 & 2 & 2 & 1 & 1 & 1 \\
S-1 & 65 & 28 & 2 & 1 & 1 & 1 & 1 & 1 \\
\hline
\end{tabular}
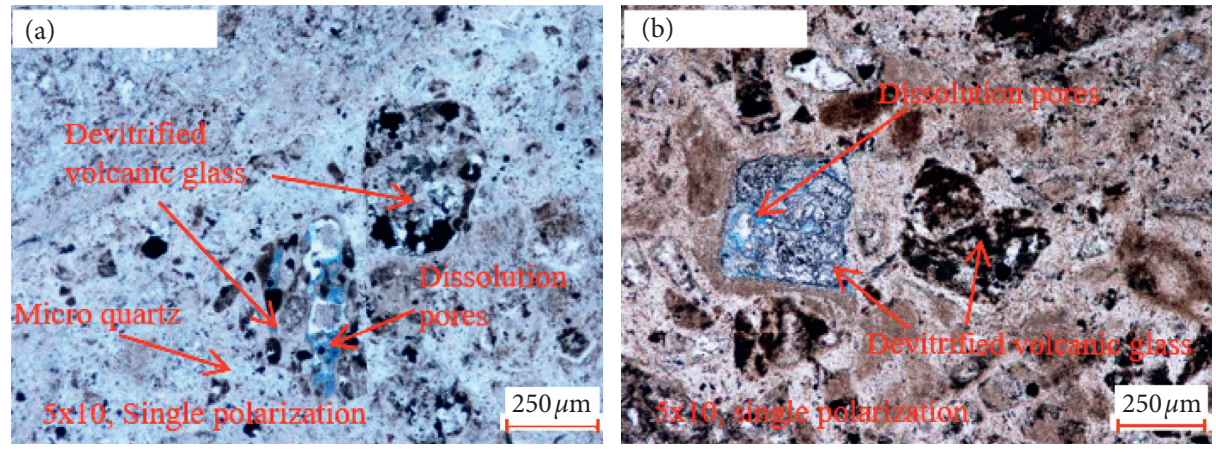

Figure 3: Polarized light microscopy image on the tunnel tuffs of Mila Mountain under dry and saturated conditions. (a) MLS-DRY. (b) MLS-SAT.

is formed after corrosion in the volcanic glass particles. By contrastive analysis, it can be found that corrosion happened interiorly in more volcanic glass after saturation, sheet porosity changed obviously, and surface porosity was increased from 1 to $2 \%$ under dry condition to $3-5 \%$ under saturated condition, confirming that tuffs porosity of tunnel in Mila Mountain increased after saturation and corrosion.

In Figure 4 , the mean $P$-wave velocity of the tuffs under saturated condition in the range of $4600-4900 \mathrm{~m} / \mathrm{s}$ is $4761 \mathrm{~m} /$ $\mathrm{s}$, faster than $4681 \mathrm{~m} / \mathrm{s}$, that under dry condition in the range of $4500-4900 \mathrm{~m} / \mathrm{s}$, is increasing by $1.71 \%$, which results from the fact that the solid-gas two-phase is changed into solidliquid two-phase for the sample, while the propagation velocity of $P$-wave in water is faster than that in air; thus, the velocity increases.

\subsection{Analysis on Deformation and Fracture Characteristics.} As shown in Figures 5 and 6 in which stress-strain curves under uniaxial compression test on tuffs were depicted, the deformation curve can be divided into 4 phases, compaction, linear elasticity, peak, and postpeak. Due to porous tuffs, the first phase of compaction is generally evident; however, the compaction is not obvious in Figure 7; the stress-strain curve of sandstone, because sandstone is a typical kind of hard rock in sedimentary rocks, is featured with compact structure and primary pore inside the rock which are not developed [23]. In the experiment, the tuff porosity increased due to water corrosion and made the proportion increase at compaction phase under saturation condition. To further analyze the effect of microfracture on deformation at compaction phase, the ratio of the stress/strain value at compaction and peak phase was taken as the parameter for quantitative evaluation to calculate the proportion of compaction phase in the whole deformation process. Compared with Gao et al. [24], the stress/strain value is 0.000513 at the end phase of compaction for sandstone in
Figure 7, 0.011957 at peak phase, and the ratio is $4.3 \%$; The value is 0.001 under dry condition at the end phase of compaction, the mean is 0.002387 at peak phase, and the ratio is $38.5 \%$, while under saturated condition, it is 0.0012 at the end phase of compaction, the mean is 0.002387 at peak phase, and the ratio is $50.3 \%$, respectively. The above results verified that tuff in the tunnel of Mila Mountain possessed high porosity, and water corrosion had positive relation with porosity, which was consistent with the observation result by polarized light microscopy.

Meanwhile, under dry and saturated conditions, the stress/ strain for most of the tuff samples dropped vertically after experiencing peak stress, and the residual phases were indistinct. According to Wawersik analysis by uniaxial compression test in which stress-strain curve of rock can be classified into type I and II (Figure 8), type II was the unstable mircofracture [25]; that is, the samples possessed strain storage capacity and released suddenly; without the aid of external force, fracture occurred and expanded within the samples, which was called as brittle fracture. In this experiment, tuff samples were brittle fracture under both conditions.

The macrofracture characteristics of tuff in the tunnel of Mila Mountain under dry and saturated conditions are shown in Figure 9. Overall, after uniaxial compression test, the 3 samples presented nearly vertical and thorough macrotensile fracture under dry condition, and DRY 3 developed several tensile fracture planes. Further analysis on DRY 3 was made, and the results are shown in Figure 9(c), in which the sample was fractured immediately into block masses and many tiny rocks after the rubber band was loosened, and lots of failure cracks spread within the main block, proving that the fracture was complete. Furthermore, fracture surface was smooth without powder, indicating that block slippage and friction did not occur after peak stress, in consistency with the conclusion that residual stress was indistinct. And the three samples presented similar features under saturated condition, but some secondary shear fracture planes developed. 


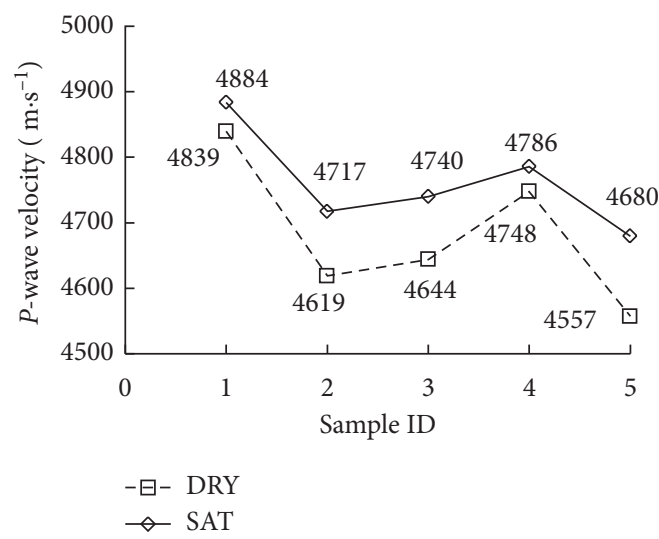

FIgure 4: $P$-wave velocity test results of tuff in Mila Mountain tunnel under dry and saturated conditions.

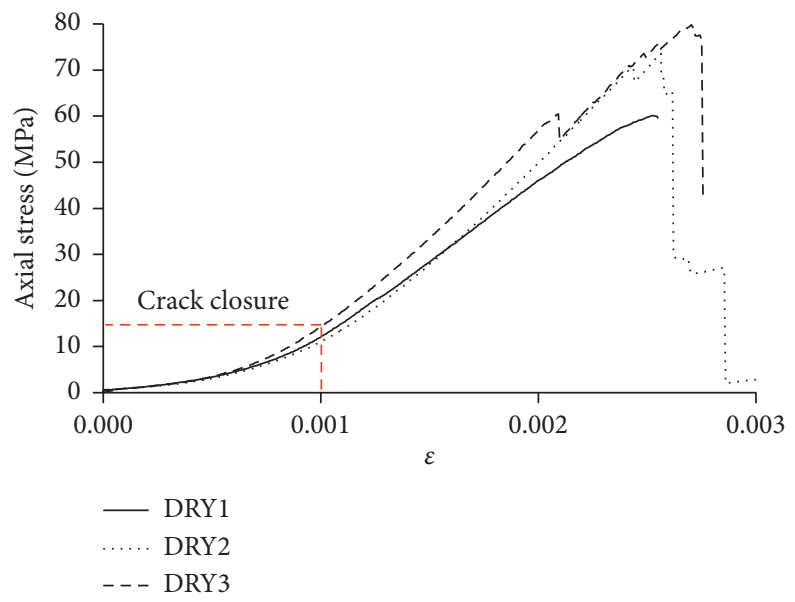

FIGURE 5: Tuff stress-strain curves under dry condition obtained from uniaxial compression test.

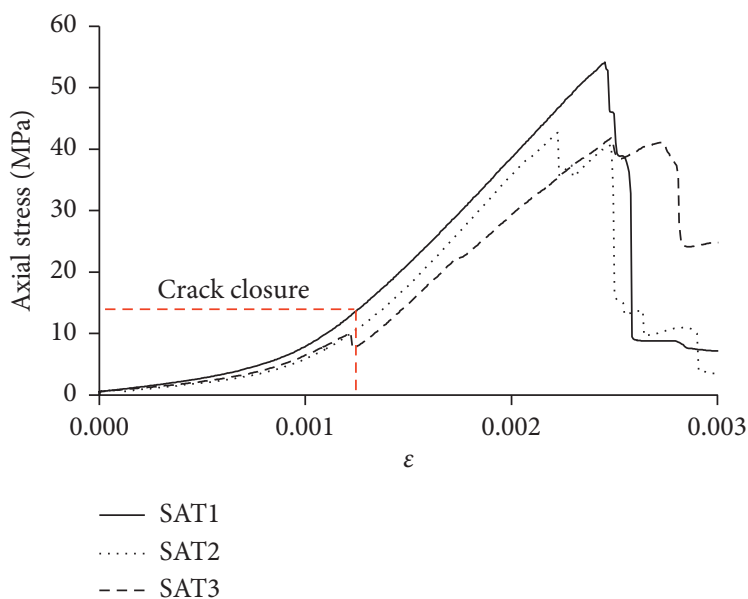

FIgURE 6: Tuff stress-strain curves under saturated condition obtained from uniaxial compression test.

It can be seen from the experiments of optical microscopic observation and wave velocity testing that the pore development of tuffs in the tunnel of Mila Mountain was the typical inhomogeneous media, and the fracture process was microcrack formation, development, and convergence with the occurrence, evolution of different types of cracks including transcrystalline crack, intergranular crack, and the coupling. In Figure 10, typical samples of DRY 3 and SAT 1 after fracture were the objects for SEM to analyze the microstructure, fracture distribution characteristics of fracture surface, in which under dry condition, the tuff surface was coated with clay and the structure was compact, though the 


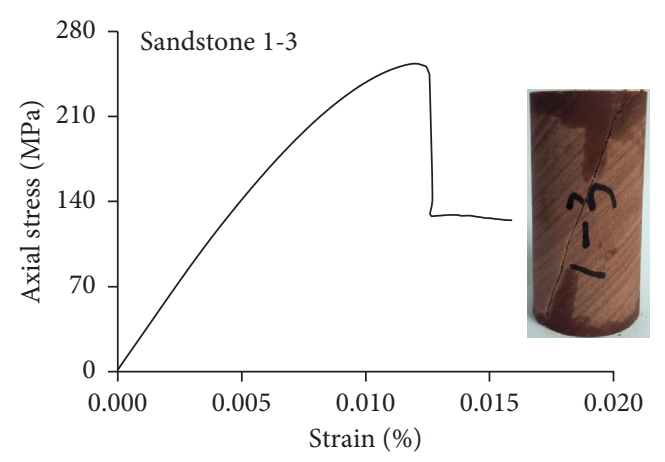

Figure 7: The stress-strain curve of a sandstone [24].

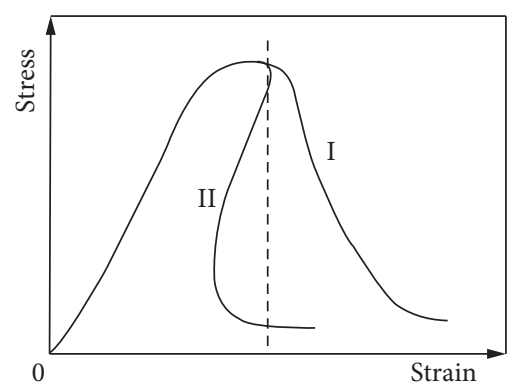

Figure 8: Rock failure types after uniaxial compression [25].

cracks with diameter $300 \mu \mathrm{m}$ were observable on the surface, and clear cracks inside the tuff and transcrystalline crack, as well as few grains with diameter $50 \mu \mathrm{m}$ on the surface when amplified, indicating that the mechanical behavior of the samples performed well to some extent. While under saturated condition, although the tuff surface was coated with clay as well, the structure was incompact, on which there were more pores and a mass of micro mineral grains with diameter $300 \mu \mathrm{m}$; in addition, no observable cracks but distinct mineral grains with diameter $50 \mu \mathrm{m}$ indenting can be found on the surface when amplified, indicating the poor mechanical behavior of the sample. Through comparison, the reason for the degraded mechanical behavior of tuff under saturated condition was that due to water corrosion, tuff porosity increased, then the structure became incompact, strength was lowered, and mechanical property was weakened, though no observable cracks were developed on the surface.

3.3. Mechanical Parameter Analysis. Figures 11 and 12 depicted the details of tuff in the tunnel of Mila Mountain under dry and saturated conditions at peak phase, in which the relationship between peak stress and strain at peak stress was positive in general, excluding SAT-3. Respectively, the mean peak stress was $71.2 \mathrm{MPa}$ and $46.2 \mathrm{MPa}$, and the mean strain at peak stress was 0.002595 and 0.002387 under dry and saturated condition, revealing that the tuff mechanical behavior was degraded after saturation as the stress decreased by $35 \%$, and the strain at peak stress decreased by $8 \%$, compared with that under dry condition.
Figure 13 is the elastic modulus of tuff in the tunnel of Mila Mountain under dry and saturated conditions in which the mean elastic modulus was $34.2 \mathrm{GPa}$ and $19.8 \mathrm{GPa}$, respectively, reduced by $42 \%$, revealing that effect of water softening on the mechanical behavior of tuff was significant.

3.4. Mechanism. Mineral compositions and structural features were studied in this section to explain the mechanism that tuff was characterized by increased porosity, wave velocity, and lowered strength after saturation, which were concluded from the above experiments.

It can be learnt from Table 1 that clay minerals, accounting for larger proportion, 30\%, in the tuff compositions, included several kinds of hydrophilic expansive minerals, such as montmorillonite, illite, and kaolinite. During saturation, illite can be transformed into clay mineral having high expansibility, for example, montmorillonite or kaolinite; on the other hand, due to the fact that for montmorillonite minerals, its lattice activity had a close relationship with the internal surface which can adsorb larger number of water molecules, $c$-axis interplanar crystal spacing can be fully expanded to $600 \AA$, and the spacing was only $9.6 \AA$ under dry condition; montmorillonite minerals can be dispersed into single space unit in the extreme. Transformation and decomposition properties of hydrophilic expansive minerals of clay minerals in tuff led to the change of mineral structure and gradually grains aggregation (Figure 10(b)). With saturation time passing, grains swelled after fully submerged by water, and repulsive force was stronger than adsorption force between grains which had 


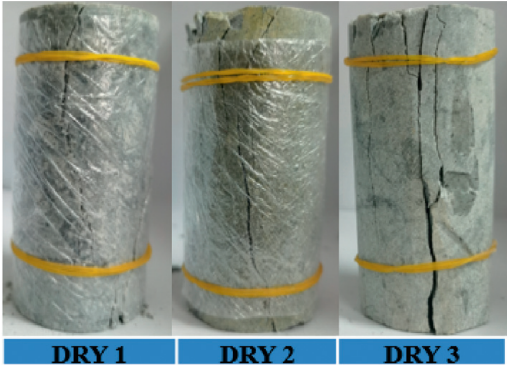

(a)

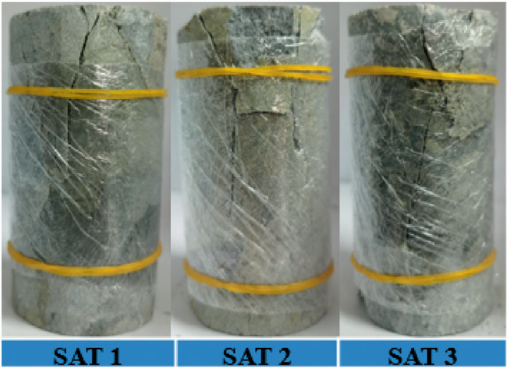

(b)

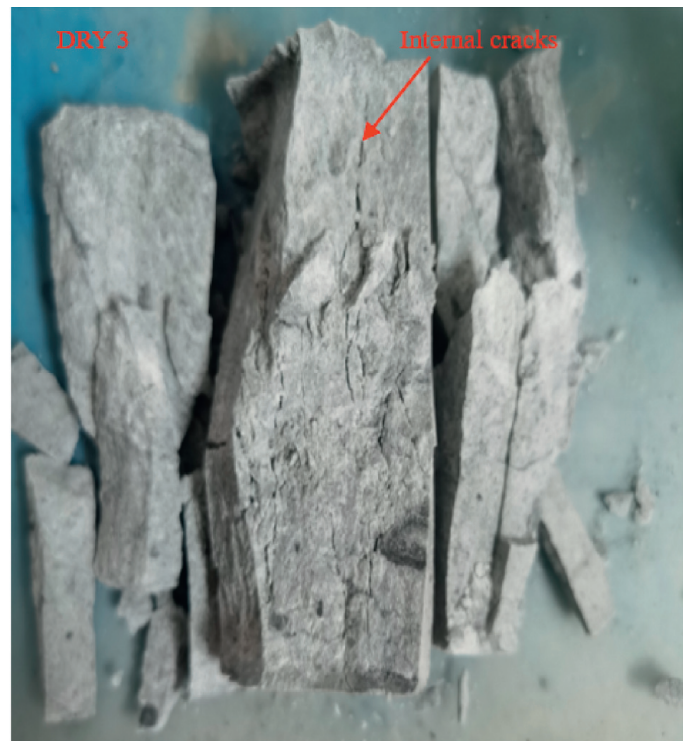

(c)

FIgURE 9: Macrofracture characteristic pattern of the tuffs in the tunnel of Mila Mountain after uniaxial compression.

thick hydration shells, leading to the structure failure and lower stress. In terms of rock structure, initial fissure, porosity developed well in the tuff sample, during saturation, water flowed into the sample along cracks and pores, then swelling, softening occurred; meanwhile, hydration shells absorbed on fine grains which were generated from water corrosion accelerated the volume swelling. The anisotropic swelling force made the anisotropic stress in the sample, triggering the change of pore structure and then grains movement, further swelling, softening, and disaggregation. In addition, cements in the sample contained $\mathrm{K}^{+}, \mathrm{Na}^{+}, \mathrm{Ca}^{2+}$, $\mathrm{Mg}^{2+}, \mathrm{S}^{2-}$, and $\mathrm{Cl}^{-}$ions, of which the soluble cements were dissolved or diluted after water and interaction; then, grains were disconnected and disaggregation occurred. After absorbing water, the phase state of the icons existing in pore solution changed and the ions was crystallized, leading to the sample volume swelling; for example, the chemical formula for anhydrite volume swelling was shown as $\mathrm{CaSO}_{4}+2 \mathrm{H}_{2} \mathrm{O} \longrightarrow \mathrm{CaSO}_{4} \bullet 2 \mathrm{H}_{2} \mathrm{O}$.

Finally, tuff in the tunnel of Mila Mountain contained a proportion of pyrite, a kind of mineral which was unstable, easy to weathering, and possessed strong reducibility. Fe and $\mathrm{S}$ in pyrite were reductive chemical elements of lower valence extremely easy to oxidation. Sulfuric acid generated from the oxidization of lower valence sulfur corroded the tuff due to its acidity; further, it made combination reaction with other minerals; then, sulfate was produced. Sulfuric acid and sulfate were dissolved and washed away in water, accelerating tuff development and loosening the structure, which further provided passage for water into tuff.

According to the above analysis, the reason for the content reductions of clay minerals, anhydrite and pyrite, in the tuffs in the tunnel of Mila Mountain was water corrosion after saturation. The mechanism of water softening tuff was that soluble minerals in tuff were corroded and swelled after water; then new grains were generated and moved with the ions in pores, dissolving, loosening and softening the tuff structure; finally, its mechanical behavior was degraded.

\section{Constitutive Model on Tuff in the Tunnel of Mila Mountain}

4.1. Model Selection. A reasonable constitutive model considering water softening effect is the key to accurate prediction and judgment of the reliability and stability of rock engineering, such as tunnel surrounding rock stability and water inrush numerical calculation. Therefore, the author would like to establish the constitutive model of tuff under dry and saturated conditions. Based on the experimental results of polarized light microscope experiment, tuff in the 



FIgURE 10: Microfracture characteristic pattern of the tuffs in the tunnel of Mila Mountain after uniaxial compression. (a) DRY 3. (b) SAT 1.

tunnel of Mila Mountain was the compacted combination of volcaniclastic material with diameter less than $3 \mathrm{~mm}$, hydrolyzed materials by tephra or cemented clay materials, characterized by high porosity, fine granularity, and grains of large specific surface area. The conventional elasticity or elastic-plastic model failed to explain the deformation mechanism; nonlinearity and drop at postpeak on the stressstrain curve were distinct. Assumed that the microstructure of the rock presented masses of cracks and randomly distributed pores, damage statistical constitutive model could be applied to explain the nonlinear characteristic on the basis of interior defects in rock. Thus, considering the characteristics of high porosity and nonlinear stress-strain curves of the tuff in the Milashan tunnel, a damage statistical constitutive model was selected to describe the constitutive behavior of the tuff under dry and saturated water conditions.

4.2. Model Building. Researches on damage statistical constitutive model on rock have made great improvement, thanks to the introduction of damage statistical theory. According to the random distribution of defects in rock materials and Weibull distribution of microelement strength of rock, many scholars have established the corresponding statistical damage constitutive model of rock based on the results of rock compression tests [26-29]. The applicability of damage statistical constitutive model to tuff before and after saturation was explored, based on the previous studies. Affected by interior defects existing in rock such as random distributed pores, cracks, joints, etc., rock strength was undetermined and randomly changed. The strength of microelements was not exactly the same, and according to damage mechanism, the process was continuous from the beginning of damage to failure. Therefore, there are assumptions as follows [30, 31]:

(1) Rock is isotropy macroscopically.

(2) Microelement has two states: failure and nonfailure.

(3) Microelement before failure complies with Hooke's law.

(4) Though strengths of microelements are not the same, but comply with Weibull distribution law, and its probability density function is

$$
P(F)=\frac{m}{F_{0}}\left(\frac{F}{F_{0}}\right)^{m-1} \exp \left[-\left(\frac{F}{F_{0}}\right)^{m}\right],
$$

where $F$ is microelement strength and $m$ and $F_{0}$ are the parameters of Weibull distribution law, indicating the mechanical property of rock.

Continuous failures of microelements could degrade rock properties and induce fracture. $N_{f}$ is the amount of damaged microelements on some stress condition, the ratio of the total amount of failures to the sum of microelements $(N)$ is called a statistical damage variable, and the equation is

$$
D=\frac{N_{f}}{N} .
$$

When the stress is set to be $F$, then the amount of the damaged microelements $N_{f}$, is

$$
N_{f}=\int_{0}^{F} N f(\sigma) d \sigma=N \int_{0}^{F} f(\sigma) d \sigma=N\left\{1-\exp \left[-\left(\frac{F}{F_{0}}\right)^{m}\right]\right\} .
$$

Damage variable $D$ is calculated by substituting equation (3) into (2): 


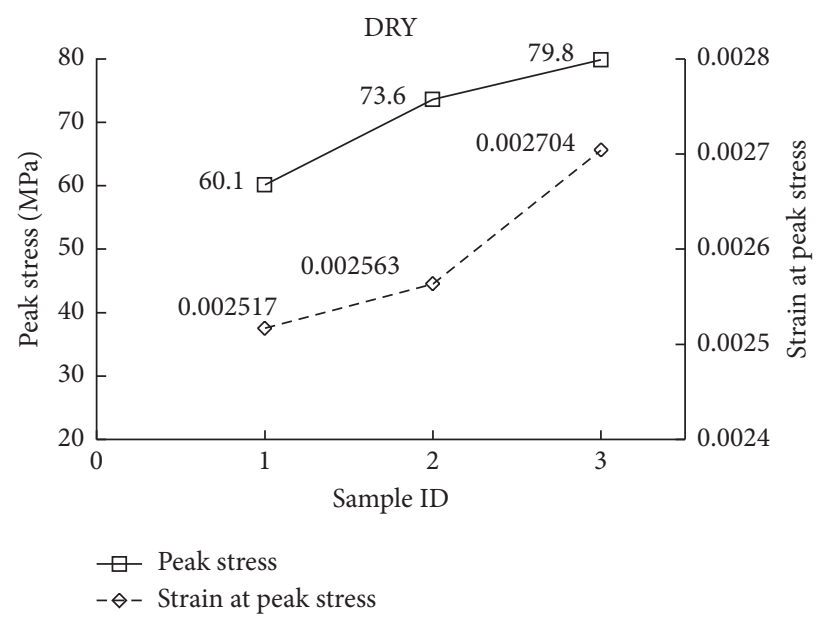

Figure 11: Pattern of the tuffs in the tunnel of Mila Mountain at peak phase under dry condition.

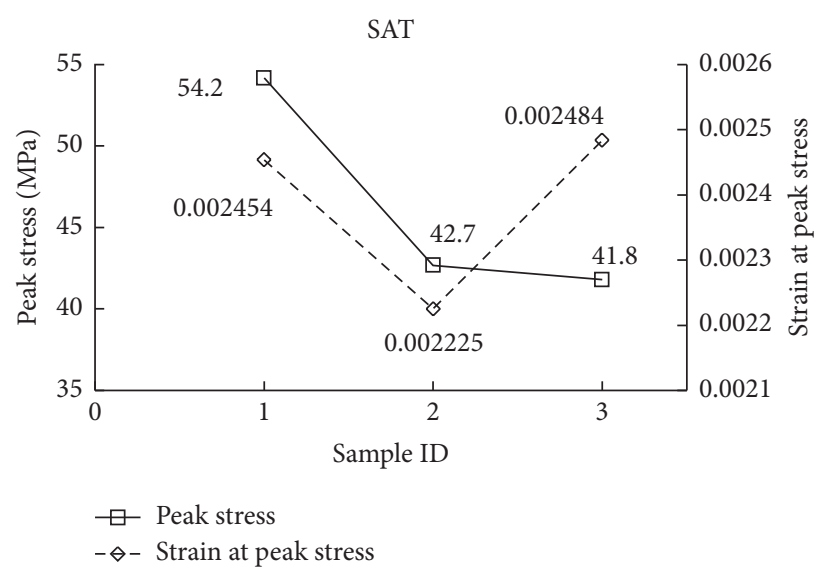

Figure 12: Pattern of the tuffs in the tunnel of Mila Mountain at peak phase under saturated condition.

$$
D=1-\exp \left[-\left(\frac{F}{F_{0}}\right)^{m}\right]
$$

Drucker-Prager law is taken to judge the microelement damage in rock; that is,

$$
\begin{aligned}
F & =f(\sigma) \\
& =\alpha_{0} I_{1}+\sqrt{J_{2}} .
\end{aligned}
$$

$\alpha_{0}=\sin \varphi / \sqrt{9+3 \sin ^{2} \varphi}$, of which $I_{1}$ is the first invariant of stress tensor, $J_{2}$ is the second invariant of stress tensor, and their calculations are shown as follows:

$$
\begin{aligned}
& I_{1}=\sigma_{x}^{*}+\sigma_{y}^{*}+\sigma_{z}^{*}=\sigma_{1}^{*}+\sigma_{2}^{*}+\sigma_{3}^{*} \\
& J_{2}=\frac{1}{6}\left[\left(\sigma_{1}^{*}-\sigma_{2}^{*}\right)^{2}+\left(\sigma_{2}^{*}-\sigma_{3}^{*}\right)^{2}+\left(\sigma_{3}^{*}-\sigma_{1}^{*}\right)^{2}\right] .
\end{aligned}
$$

$F$, the random variable, is selected to get damage statistical constitutive model, according to the Drucker-Prager law and strain equivalence theory of Lemaitre [30, 31], as follows:

$$
\sigma_{i}=E \varepsilon_{i} \exp \left[-\left(\frac{F}{F_{0}}\right)^{m}\right]+\mu\left(\sigma_{j}+\sigma_{k}\right)
$$

According to the research results of Cao and $\mathrm{Li}[30,31]$, constitutive parameters, $m$ and $F_{0}$, are calculated below under uniaxial condition:

$$
m=\frac{1}{\operatorname{In}\left(E \varepsilon_{c} / \sigma_{c}\right)} .
$$

$$
\left(\frac{F_{c}}{F_{0}}\right)^{m}=\frac{1}{m}
$$

where $E$ is elasticity modulus, $\sigma_{c}$ is peak strength, $\varepsilon_{c}$ is the strain at peak strength, and $F_{c}$ corresponds to $F$ at peak strength.

4.3. Model Verification. Through comparison between theory result and uniaxial test result on tuff samples from the tunnel of Mila Mountain under dry and saturated conditions, the constitutive model was verified as shown in Figure 14 in which 


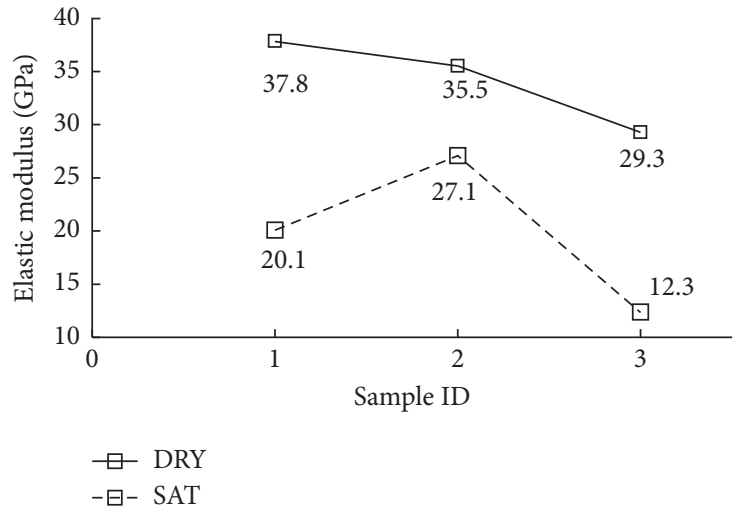

FIgURE 13: Elastic modulus of tuff in the tunnel of Mila Mountain under dry and saturated conditions.

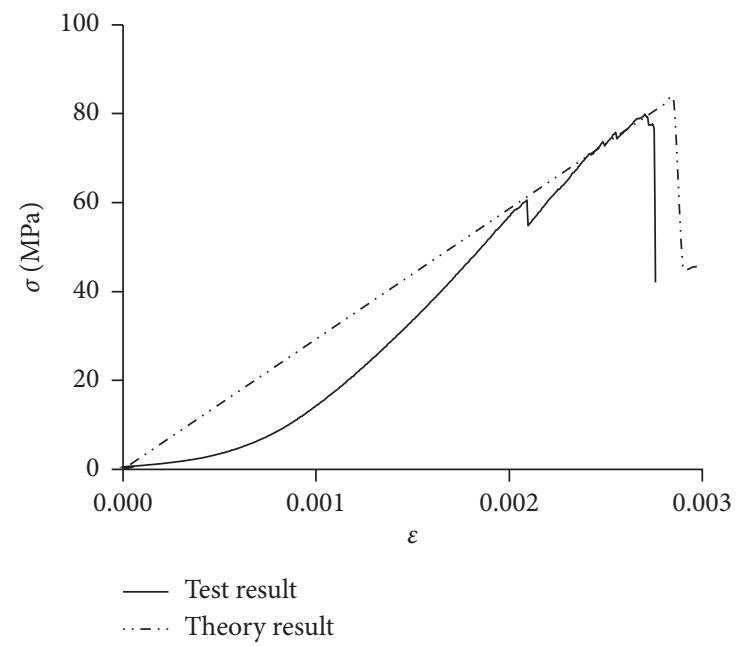

(a)

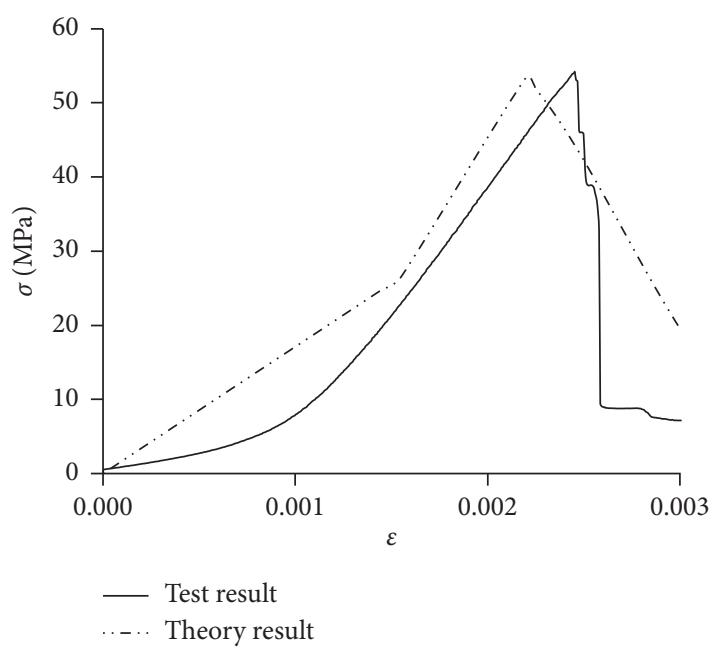

(b)

FIGURE 14: Experimental and theoretical stress-strain curves under dry and saturated conditions. (a) DRY 3. (b) SAT 1.

the two curves, test result and theory result, matched well in general, indicating that damage statistical constitutive model was applicable to express tuff constitutive behaviors.

\section{Conclusion}

This paper, in order to provide some theoretical and data support for the construction of tuff tunnel, the physicomechanical parameters, failure mechanism, and constitutive model of tuff in Mila Mountain tunnel under dry and saturated conditions were studied by experimental and theoretical analytical methods. According to the experimental results, water softening mechanism and mechanical characteristics have been analysed under dry and saturated conditions; then, the stress-strain curves from tests were simulated by a damage statistical constitutive model; finally, the conclusion can be made as follows.

(1) Quartz and clay minerals were dominated in tuff compositions in the tunnel of Mila Mountain, accounting for more than $90 \%$, and quartz content increased after saturation, while clay minerals content was reduced.

(2) Soluble minerals were corroded in the tuff after saturation, and porosity and wave velocity increased; however, elasticity modulus and peak strength were lowered severely, reaching $42 \%$ and 35\%, respectively.

(3) The mechanical characteristics of tuff after saturation were determined by the mineral compositions and structure characteristics of tuff in the tunnel of Mila Mountain; specifically, as the tuff characterized by high porosity convenient for water infiltration, the soluble minerals in the tuff were corroded and swelled by water; then, new grains were generated and moved with the ions in pores, dissolving, loosening, and softening the tuff structure; then, its mechanical properties were degraded.

(4) Theory result and test result matched well under dry and saturated conditions, revealing that damage statistical constitutive model was applicable to 
express the constitutive behavior of tuff in the tunnel of Mila Mountain.

\section{Data Availability}

The datasets used and analysed during this study are included within the manuscript.

\section{Conflicts of Interest}

None of the authors have any conflicts of interest regarding the publication of this study.

\section{References}

[1] E. Emir, A. Konuk, and G. Daloğlu, "Strength enhancement of Eskisehir tuff ashlars in Turkey," Construction and Building Materials, vol. 25, no. 7, pp. 3014-3019, 2011.

[2] C. Di Benedetto, P. Cappelletti, M. Favaro et al., "Porosity as key factor in the durability of two historical building stones: neapolitan yellow tuff and Vicenza stone," Engineering Geology, vol. 193, pp. 310-319, 2015.

[3] S. Peng, X. Li, Z. Wu, J. Chen, and X. Lu, "Study of the key technologies of application of tuff powder concrete at the Daigo hydropower station in Tibet," Construction and Building Materials, vol. 156, pp. 1-8, 2017.

[4] A. Ababneh and F. Matalkah, "Potential use of Jordanian volcanic tuffs as supplementary cementitious materials," Case Studies in Construction Materials, vol. 8, pp. 193-202, 2018.

[5] B. Balegh, H. Sellaf, and A. Hadjmostefa, "Effect of ceramic waste on mechanical and geotechnical properties of tuff treated by cement," Case Studies in Construction Materials, vol. 13, Article ID e00368, 2020.

[6] A. Yassaghi, H. Salari-Rad, and H. Kanani-Moghadam, "Geomechanical evaluations of Karaj tuffs for rock tunneling in Tehran-Shomal Freeway, Iran," Engineering Geology, vol. 77, no. 1-2, pp. 83-98, 2005.

[7] M. B. Gray, J. A. Stamatakos, D. A. Ferrill, and M. A. Evans, "Fault-zone deformation in welded tuffs at Yucca Mountain, Nevada, USA," Journal of Structural Geology, vol. 27, no. 10, pp. 1873-1891, 2005.

[8] T. Topal and V. Doyuran, "Engineering geological properties and durability assessment of the Cappadocian tuff," Engineering Geology, vol. 47, no. 1-2, pp. 175-187, 1997.

[9] T. Esaki and K. Jiang, "Comprehensive study of the weathered condition of welded tuff from a historic stone bridge in Kagoshima, Japan," Engineering Geology, vol. 55, pp. 121-130, 1999.

[10] A. Çavdar and Ş. Yetgin, "Availability of tuffs from northeast of Turkey as natural pozzolan on cement, some chemical and mechanical relationships," Construction and Building Materials, vol. 21, no. 12, pp. 2066-2071, 2007.

[11] M. U. Toprak and M. A. Arslanbaba, "Possibility of using Kütahya volcanic tuff as building stone: microstructural evaluation and strength enhancement through heat treatment," Construction and Building Materials, vol. 110, pp. 128-134, 2016.

[12] E. Ekinci, I. Türkmen, F. Kantarci, and M. B. Karakoç, "The improvement of mechanical, physical and durability characteristics of volcanic tuff based geopolymer concrete by using nano silica, micro silica and styrene-butadiene latex additives at different ratios," Construction and Building Materials, vol. 201, pp. 257-267, 2019.
[13] Y. Hadj aissa, I. Goual, and B. Benabed, "Mix-design and properties of self-compacting concrete made with calcareous tuff," Journal of Building Engineering, vol. 27, Article ID 100997, 2020.

[14] M. Korkanç and B. Solak, "Estimation of engineering properties of selected tuffs by using grain/matrix ratio," Journal of African Earth Sciences, vol. 120, pp. 160-172, 2016.

[15] Y. G. Xiao, C. H. Li, J. Cao, Y. Wang, Z. Q. Hou, and N. Hu, "Investigation of the effects of freeze-thaw cycles on geomechanical and acoustic characteristics of tuff specimens under different stress paths," Advances in Civil Engineering, vol. 2020, Article ID 6689181, 20 pages, 2020.

[16] T. Topal and B. Sözmen, "Deterioration mechanisms of tuffs in Midas monument," Engineering Geology, vol. 68, no. 3-4, pp. 201-223, 2003.

[17] R. Salve, J. S. Y. Wang, and C. Doughty, "Liquid-release tests in unsaturated fractured welded tuffs: I. Field investigations," Journal of Hydrology, vol. 256, no. 1-2, pp. 60-79, 2002.

[18] C. Doughty, R. Salve, and J. S. Y. Wang, "Liquid-release tests in unsaturated fractured welded tuffs: II. Numerical modeling," Journal of Hydrology, vol. 256, no. 1-2, pp. 80-105, 2002.

[19] M. Beiki, A. Majdi, and A. D. Givshad, "Application of genetic programming to predict the uniaxial compressive strength and elastic modulus of carbonate rocks," International Journal of Rock Mechanics and Mining Sciences, vol. 63, pp. 159-169, 2013.

[20] J. W. Martin, J. T. Fredrich, C. W. Felice, and S. J. Green, "Mechanical properties and microstructure of shock-conditioned tuff," International Journal of Rock Mechanics and Mining Science \& Geomechanics Abstracts, vol. 30, no. 7, pp. 669-675, 1993.

[21] L. Li, Y. Tan, B. Huang, and X. Deng, "Pore property as an indicator of macro-deterioration in slightly weathered tuffs," Engineering Geology, vol. 267, Article ID 105492, 2020.

[22] T. C. Chen, M. R. Yeung, and N. Mori, "Effect of water saturation on deterioration of welded tuff due to freeze-thaw action," Cold Regions Science and Technology, vol. 38, no. 2-3, pp. 127-136, 2004.

[23] Y. Togashi, T. Imano, M. Osada, K. Hosoda, and K. Ogawa, "Principal strain rotation of anisotropic tuff due to continuous water-content variation," International Journal of Rock Mechanics and Mining Sciences, vol. 138, Article ID 104646, 2021.

[24] M. B. Gao, T. B. Li, L. B. Meng, C. C. Ma, and H. L. Xing, "Identifying crack initiation stress threshold in brittle rocks using axial strain stiffness characteristics," Journal of Mountain Science, vol. 15, no. 6, pp. 1371-1382, 2018.

[25] W. R. Wawersik and C. Fairhurst, "A study of brittle rock fracture in laboratory compression experiments," International Journal of Rock Mechanics and Mining Science and Geomechanics Abstracts, vol. 7, no. 5, pp. 561-575, 1970.

[26] D. Krajcinovic and M. A. G. Silva, "Statistical aspects of the continuous damage theory," International Journal of Solids and Structures, vol. 18, no. 7, pp. 551-562, 1982.

[27] J. Lemaitre, "A continuous damage mechanics model for ductile fracture," Journal of Engineering Materials and Technology, vol. 107, no. 1, pp. 83-89, 1985.

[28] X. Li, W. G. Cao, and Y. H. Su, "A statistical damage constitutive model for softening behavior of rocks," Engineering Geology, vol. 143-144, pp. 1-17, 2012.

[29] M. Gao, T. Li, T. Wei, and L. Meng, "A statistical constitutive model considering deterioration for brittle rocks under a coupled thermal-mechanical condition," Geofluids, vol. 2018, Article ID 3269423, 10 pages, 2018. 
[30] W. G. Cao and X. Li, "A new discussion on damage softening statistical constitutive model for rocks and method for determining its parameters," Rock and Soil Mechanics, vol. 29, no. 11, pp. 2952-2956, 2008.

[31] M. H. Yang, M. H. Zhao, and W. G. Cao, "Method for determining the parameters of statistical damage softening constitutive model for rock," Journal of Hydraulic Engineering, vol. 36, no. 3, 2005. 